•综述・

\title{
栽培茶树的驯化起源与传播
}

\author{
张文驹 ${ }^{1 *}$ 戎 俊 ${ }^{2}$ 韦朝领 ${ }^{3}$ 高连明 4 陈家宽 ${ }^{1,2}$ \\ 1 (复旦大学生物多样性和生态工程教育部重点实验室, 上海 200438) \\ 2 (南昌大学生命科学研究院流域生态学研究所, 南昌大学生命科学学院, 南昌 330031) \\ 3 (安徽农业大学省部共建茶树生物学与资源利用国家重点实验室, 合肥 230036) \\ 4 (中国科学院昆明植物研究所东亚植物多样性与生物地理学重点实验室, 昆明 650201)
}

\begin{abstract}
摘要: 茶作为世界上最重要的饮品之一, 其栽培类型的驯化起源一直是人们关注的热点。本文总结了近年相关研 究的进展, 讨论了存在的问题, 并对未来的研究方向提出建议。长江流域及以南地区分布有众多栽培茶树的野生 近缘种, 特别集中于云南、贵州、广西等地; 一方面南方各族语言中“茶”发音的相似, 暗示了茶知识起源的单一性, 最可能起源于古代的巴蜀或云南, 另一方面遗传分析揭示栽培的茶存在多个起源中心, 即使Camellia sinensis (L.) O. Kuntze的几个栽培变种也可能起源于不同的地区; 文献记载, 茶的栽培中心曾经从西向东再向南迁移, 遗传多 样性的变化也揭示了这一可能性, 但考古发现却提示最早的栽培茶可能出现在长江流域的最东部。我们推测在茶 知识及栽培品种的传播过程中, 各地野生近缘植物的基因渗入栽培类型中, 或各地居民直接用当地野生茶培育出 新的栽培茶类型, 从而导致遗传上的复杂性和语言上的一致性并存。茶树的祖先类型、起源地点、起源时间以及 栽培品种的演变历程都还需要更为明确的证据, 未来应该以整个茶组植物为对象, 将茶文化、群体遗传学、谱系 地理、人类学、气候变化、考古等多学科研究进行整合分析。
\end{abstract}

关键词: 栽培茶; 茶组植物; 驯化起源; 茶文化; 遗传多样性

\section{Domestication origin and spread of cultivated tea plants}

\author{
Wenju Zhang $^{1^{*}}$, Jun Rong ${ }^{2}$, Chaoling $\mathrm{Wei}^{3}$, Lianming Gao ${ }^{4}$, Jiakuan Chen ${ }^{1,2}$ \\ 1 Ministry of Education Key Laboratory for Biodiversity Science and Ecological Engineering, Fudan University, Shang- \\ hai 200438 \\ 2 Center for Watershed Ecology, Institute of Life Science, Nanchang University and School of Life Sciences, Nanchang \\ University, Nanchang 330031 \\ 3 State Key Laboratory of Tea Plant Biology and Utilization, Anhui Agricultural University, Hefei 230036 \\ 4 Key Laboratory for Plant Diversity and Biogeography of East Asia, Kunming Institute of Botany, Chinese Academy of \\ Sciences, Kunming 650201
}

\begin{abstract}
Tea is the most popular non-alcoholic beverage in the world. The domestication origin of cultivated tea plants has always been a focus of ecological research. This article summarizes the recent research progress, discusses remaining questions and makes suggestions for future research directions. Many wild relatives of cultivated tea plants are distributed in the Yangtze River Basin and its southern reaches, particularly in Yunnan, Guizhou, and Guangxi provinces. The pronunciation of "cha" is similar in the languages of southern ethnic groups, implying a single domestication origin of cultivated tea plants, most likely from ancient Bashu or Yunnan. However, studies on genetic structure reveal that multiple centers occur in the domestication origin of cultivated tea plants. For example, cultivated Camellia sinensis (L.) O. Kuntze, including some varieties, may have multiple domestication events. According to research from historical text, the cultivation center of tea plants migrated from west to east and then to south, which is supported by changes in genetic diversity. However, the first cultivated tea plant might have arisen in the most eastern region of the Yangtze River Basin based on a recent archaeological finding. We speculate that during the spread of tea knowledge, cultivated varieties introgression occurred from wild relatives to cultivars, or new cultivated tea plants were directly domesticated from local wild tea plants, leading to the genetic complexity and the
\end{abstract}

收稿日期: 2018-01-08; 接受日期: 2018-03-01

基金项目: 国家自然科学基金(31670223)和国家重点基础研究计划(2014CB954103)

* 通讯作者 Author for correspondence. E-mail: wjzhang@fudan.edu.cn 
language consistency of cultivated tea plants. More evidence is needed to confirm the ancestral types, origin sites and time, and domestication processes of cultivated tea plants, and the integration anaylysis of multiple disciplines such as tea culture, population genetics, phylogeography, anthropology, climate change, and archaeology should be more encouraged.

Key words: cultivated tea plant; Sect. Thea; domestication origin; tea culture; genetic diversity

人类对重要栽培植物的驯化历史总是充满好 奇。长期以来, 研究者利用各种技术和方法千方百 计地追溯它们的进化历史, 获得了丰硕的成果 (Doebley et al, 2006; Hancock, 2012)。这些研究不仅 加深了我们对这些物种进化历史的理解, 从而能更 好地保护和利用这些重要物种的遗传资源, 而且也 使我们更加全面地理解人类文明的发展历史。同时, 研究栽培植物驯化起源与进化建立起来的理论和 方法也极大地推动了进化生物学的发展(Marcussen et al, 2014)。

茶是最为古老和全球最受欢迎的无酒精类饮 料, 它不仅对中国人的文化、健康、医药、贸易等 产生了深远的影响, 而且在亚洲乃至整个世界众多 人的日常生活中也发挥着重要作用, 茶树已成为许 多地区有重要价值的栽培植物。100多年来, 栽培茶 树的起源和进化同样吸引了众多研究者的关注 (Baildon, 1877; Wright, 1959; 吴觉农等, 1979; 朱自 振, 1982; 陈进和裴盛基, 2003; Huang et al, 2014; Meegahakumbura et al, 2016; Yang et al, 2016), 尽管 已获得一些重要进展, 但远不能与人类对小麦 (Triticum aestivum)、王米 (Zea mays)等作物的栽培历 史的认识相比, 依然存在许多争议和谜团。本文回 顾和总结了有关栽培茶树驯化起源与进化的成果, 特别是近年有关茶遗传多样性研究的相关成果, 讨 论了尚存在的问题, 并对未来的研究方向提出了 建议。

\section{1 野生茶资源的调查及新物种的发现}

任何栽培植物都有其野生祖先, 寻找栽培植物 的野生类型或野生近缘种是追寻其进化足迹最好 和最常用的方法。茶树是我国最早栽培的木本作物 之一, 有悠久的栽培历史和广阔的栽培区域, 因此, 长久以来几乎无人会怀疑栽培茶树起源于中国。但 自 19 世纪 30 年代英国人在印度东北部阿萨姆地区 发现疑似野生茶树后, 就有人提出印度阿萨姆是茶 树原产地的假说。可见野生资源调查在确认栽培植
物驯化起源中的重要性。

中国古代文献对野生茶树已有很多记载(陈宗 禁，1992)，但系统、全面的调查还是在中华人民共 和国成立后才进行，各地的茶科所、林业局、农业 及林业院校等部门都参与了野生茶树资源的调查。 经过数十年的努力, 获得了中国野生茶树资源极为 详细的信息, 相关成果见《中国古茶树》(中国茶人 联谊会和中国茶叶学会, 1994)一书及一系列文献 (陈兴琰等, 1979; 虞富莲, 1989; 郭远安, 1990; 王 平盛和虞富莲, 2002; 田永辉等, 2008; 何青元等, 2009; 李苑菱等, 2017)。这些研究发现, 在我国不仅 西南地区(包括云南、四川、重庆、贵州)分布有较 多的野生茶树, 而且在广西、广东、福建、湖南、 湖北、江西等地也有野生茶树的分布。尽管大多数 工作并未论证这些野生茶树的分类学地位及其与 栽培茶的关系, 多以野生型、过渡型和栽培型进行 划分, 但大规模野外考察获得的标本与信息推动了 栽培茶近缘种或者说茶组植物的分类学研究, 其中 张宏达和闵天禄两位先生为此做出了最为杰出的 贡献(张宏达, 1981; 张宏达和任善湘, 1998; 闵天禄, 1992, 2000)。

1958年英国学者J. H. Sealy在他的山茶属专著 A Revision of the Genus Camellia一书中, 只记录了 5 种2变种茶组植物, 包括茶 [Camellia sinensis (L.) O. Kuntze]、大理茶[C. taliensis (W. W. Smith) Melch.]、 依洛瓦底茶(C. irrawadiensis Burua)、细柄茶 $(C$. gracilipes Merrill ex Sealy)和毛肋茶( $C$. pubicosta Merrill), 其中, 茶又分中国茶变种 [C. sinensis var. sinensis (C. B. Clarke) Ridley]和阿萨姆变种 [C. sinensis var. assamica (Masters) Kitamura]。《山茶属 植物的系统研究》一书出版时, 茶组植物已增至17 种(张宏达, 1981), 到1998年《中国植物志》49卷(3) 出版时, 茶组植物增至32种。其中, 张宏达及合作 者发表新种26个, 其模式产地全部位于中国, 特别 是中国西南地区(表1)。尽管有些新种可能是已知种 类的同物异名，并在实际工作中也很难区分，但张 
表1 茶组植物的分类及栽培状况

Table 1 Taxonomy and cultivation of Sect. Thea

\begin{tabular}{|c|c|}
\hline $\begin{array}{l}\text { 种及变种 } \\
\text { Species \& variety }\end{array}$ & $\begin{array}{l}\text { 异名 } \\
\text { Synonym }\end{array}$ \\
\hline \multicolumn{2}{|c|}{$\begin{array}{l}\text { 1. 大厂茶 Camellia tachangensis Zhang } \\
\text { 1a 大厂茶 var. tachangensis F. C. Zhang }\end{array}$} \\
\hline & C. qunquelocularis Chang \\
\hline & C. tetracocca Chang \\
\hline \multicolumn{2}{|c|}{ 1b 梳齿茶 var. remotiserrata (Chang et B. H. Wang) Ming } \\
\hline & C. remotiserrata Chang, F. L. Yu et P. S. Wang \\
\hline & C. jymnogynoides Chang, F. L. Yu et P. S. Wang \\
\hline & C. nanchuanica Chang et Xiong \\
\hline & C. jingyunshanica Chang et J. H. Xiong \\
\hline
\end{tabular}

2. 大苍茶 Camellia grandibracteata Chang et $\mathrm{Yu}$

3. 广西茶 Camellia kwangsiensis Chang

3a 广西茶 var. kwangsiensis Chang

3b 广南茶 var. kwangnanica (Chang et Chen) Ming

4. 大理茶 Camellia taliensis (W. W. Smith) Melch
C. changningensis F. C. Zhang, W. R. Ding et Y. Huang
C. irrawadiensis Burua
C. pentastyla Chang
C. quinquebracteata Chang \& C. X. Ye
Polyspora yunnanensis $\mathrm{Hu}$
Gordonia yunnanensis (Hu) H. L. Li

5. 厚轴茶 Camellia crassicolumna Chang

5a 厚轴茶 var. crassicolumna (C. B. Clarke) Ridley
C. atrothea Chang \& H. S. Wang
C. crassicolumna var. shangbaensis F. C. Zhang
C. crispula Chang
C. haaniensis Chang \& F. L. Yu
C. makuanica Chang \& Y. J. Tang
C. purpurea Chang \& B. H. Chen
C. rotundata Chang \& F. L. Yu

5b 多蕶茶 var. multiplex (Chang \& Y. J. Tang) Ming

6. 老挝茶 Camellia sealyama Ming

7. 秃房茶 Camellia gymnogyna Chang

C. glaberrima Chang

8. 突肋茶 Camellia costata Hu et S.Y.Liang

$$
\begin{aligned}
& \text { C. danzaiensis K. M. Lan } \\
& \text { C. kwangtungensis Chang } \\
& \text { C. yungkiangensis Chang }
\end{aligned}
$$

9. 膜叶茶 Camellia leptophylla S. Y. Liang et Chang

10. 防城茶 Camellia fengchengensis Liang et Zhong

11. 毛叶茶 Camellia ptilophylla Chang

C. pubescens Chang et C. X. Ye

12. 茶 Camellia sinensis (L.) O. Kuntze

12a 茶(小叶茶) var. sinensis (C. B. Clarke) Ridley

模式产地 生境 ${ }^{*}$

Type locality Habitat $^{*}$

云南师宗 Shizong, Yunnan, China

W

云南师宗 Shizong, Yunnan, China W

广西隆林 Longlin, Guangxi, China -

贵州普安 Pu'an, Guizhou, China

云南威信 Weixin, Yunnan, China W

云南威信 Weixin, Yunnan, China -

云南盐津 Yanjin, Yunnan, China -

重庆南川 Nanchuan, Chongqing, China -

重庆北碚 Beibei, Chongqing, China

云南云县 Yunxian, Yunnan, China

广西田林 Tianlin, Guangxi, China

C

广西田林 Tianlin, Guangxi, China W

云南广南 Guangnan, Yunnan, China W

云南大理 Dali, Yunnan, China W \& C

云南昌宁 Changning, Yunnan, China -

缅甸依洛瓦底 Irrawaddy, Burma -

云南凤庆 Fengqing, Yunnan, China -

云南梁河 Lianghe, Yunnan, China -

云南潞西 Luxi, Yunnan, China -

云南潞西 Luxi, Yunnan, China -

云南西畴 Xichou, Yunnan, China W

云南西畴 Xichou, Yunnan, China W

云南屏边 Pingbian, Yunnan, China -

云南镇元 Zhenyuan, Yunnan, China -

云南金平 Jinping, Yunnan, China -

云南金平 Jinping, Yunnan, China -

云南马关 Maguan, Yunnan, China -

云南屏边 Pingbian, Yunnan, China -

云南红河 Honghe, Yunnan, China -

云南文山 Wenshan, Yunnan, China W

老挝沙拉湾省 Salavan, Laos U

广西凌云 Lingyun, Guangxi, China W

云南屏边 Pingbian, Yunnan, China -

广西昭平 Zhaoping, Guangxi, China W

贵州丹寨 Danzhai, Guizhou, China -

广东阳山 Yangshan, Guangdong, China -

贵州榕江 Rongjiang, Guizhou, China -

广西龙州 Longzhou, Guangxi, China W

广西防城 Fangcheng, Guangxi, China W

广东龙门 Longmen, Guangdong, China W \& C

湖南汝城 Rucheng, Hunan, China -

中国福建 Fujian, China W \& C

中国福建 Fujian, China W \& C 
表 1 (续) Table 1 (continued)

\begin{tabular}{|c|c|c|c|}
\hline $\begin{array}{l}\text { 种及变种 } \\
\text { Species \& variety } \\
\end{array}$ & $\begin{array}{l}\text { 异名 } \\
\text { Synonym }\end{array}$ & $\begin{array}{l}\text { 模式产地 } \\
\text { Type locality }\end{array}$ & $\begin{array}{l}\text { 生境* } \\
\text { Habitat* }\end{array}$ \\
\hline & Thea sinensis L. & 中国福建 Fujian, China & - \\
\hline & C. arborescens Chang \& F. L. Yu & 云南威信 Weixin, Yunnan, China & - \\
\hline & C. longlingensis F. C. Zhang et al & 云南龙陵 Longling, Yunnan, China & - \\
\hline & C. oleosa (Loureiro) Rehder & 未知 Unknow & - \\
\hline & C. sinensis f. formosensis Kitamura & 中国台湾 Taiwan, China & - \\
\hline & C. waldeniae S. Y. Hu & 中国香港 Hong Kong, China & - \\
\hline & C. thea Link & 未知 Unknow & - \\
\hline & T. bohea L. & 福建武夷 Wuyi, Fujian, China & - \\
\hline & T. cantonensis Loureiro & 未知 Unknow & - \\
\hline & T. chinensis Sims & 未知 Unknow & - \\
\hline & T. cochinchinensis Loureiro & 未知 Unknow & - \\
\hline & T. grandifolia Salisbury & 未知 Unknow & - \\
\hline & T. olearia Loureiro ex Gomes & 未知 Unknow & - \\
\hline & T. oleosa Loureiro & 未知 Unknow & - \\
\hline & T. parvifolia Salisbury, not Hayata & 未知 Unknow & - \\
\hline & T. sinensis var. macrophylla Siebold & 台湾 Taiwan & - \\
\hline & T. sinensis var. parvifolia Miquel & 未知 Unknow & - \\
\hline & T. viridis $\mathrm{L}$ & 未知 Unknow & - \\
\hline & Theaphylla cantonensis (Loureiro) Rafinesque & 未知 Unknow & - \\
\hline $12 b$ 大叶茶 & Issamica (Masters) Kitamura & 印度阿萨姆 Assam, India & $\mathrm{W} \& \mathrm{C}$ \\
\hline & Thea assamica Masters & 印度阿萨姆 Assam, India & W \& C \\
\hline & C. multisepala Chang \& Y. J. Tang & 云南秒腊 Mengla, Yunnan, China & - \\
\hline & C. polyneura Chang \& Y. J. Tang & 云南绿春 Lüchun, Yunnan, China & - \\
\hline & C. sinensis var. kucha Chang \& H. S. Wang & 云南金平 Jinping, Yunnan, China & - \\
\hline 12c 德宏茶 & lehungensis (Chang \& B. H. Chen) Ming & 云南德宏 Dehong, Yunnan, China & $\mathrm{W} \& \mathrm{C}$ \\
\hline & C. dehungensis Chang \& B. H. Chen & 云南德宏 Dehong, Yunnan, China & - \\
\hline & C. manglaensis Chang, Tan et wang & 云南㐨腊 Mengla, Yunnan, China & - \\
\hline & C. parvisepaloides Chang \& H. S. Wang & 云南潞西 Luxi, Yunnan, China & - \\
\hline & C. gymnogynoides Chang et Chen & 云南预腊 Mengla, Yunnan, China & - \\
\hline 12d 白毛茶 & ubilimba Chang & 广西凌云 Lingyun, Guangxi, China & $\mathrm{W} \& \mathrm{C}$ \\
\hline & C. angustifolia Chang & 广西金秀 Jinxiu, Guangxi, China & - \\
\hline & C. dishiensis F. C. Zhang, X. Y. Chen et G. B. Chen & 云南广南 Guangnan, Yunnan, China & - \\
\hline & C. parvisepala Chang & 广西凌云 Lingyun, Guangxi, China & - \\
\hline 12e 高棉茶 & asiocalyx (G. Watt) A.P. Das \& C. Ghosh ${ }^{* *}$ & 柬埔寨 Cambodia & $\mathrm{C}$ \\
\hline
\end{tabular}

* 生境类型: $\mathrm{W}$ 表示野生, C表示栽培, $\mathrm{U}$ 表示未知, - 表示与合法分类群相似; ** 闵天禄系统中并未对这一名称进行处理。

* Habitats: W indicates wild, C indicates cultivated, U indicates unknow, - indicates similar to the accepted taxon; ** This variety was not listed in Ming's taxonomy on the section Thea, Camellia.

\section{宏达等的工作还是极大地推动了我们对栽培茶野} 生近缘种的认识, 成为研究栽培茶起源的重要基础。

在上述工作基础上，闵天禄(1992，2000)先后 两次对茶组植物进行修订，根据花柱离生、苞片宿 存将毛肋短芯茶(C. pubicosta Merr.)从茶组分出, 并 将其他茶组植物归并为 12 种 10 变种 (表1), 其中老挝 茶(C. sealyama Ming)为新种。闵天禄先生的修订一 定程度上澄清了茶组植物种类划分过细的问题,
Flora of China采用了闵天禄的系统。按照这一分类 系统，广泛栽培的茶树属于 C. sinensis (L.) O. Kuntze下的两个变种: 阿萨姆变种(俗称大叶茶, 下 同)和中国茶变种(俗称小叶茶，下同); 除此之外, 还有多个种或变种也被少量栽培, 包括大理茶、大 苞茶(C. grandibracteata Chang et Yu)、德宏茶 $[C$. sinensis var. dehungensis (Chang \& B. H. Chen) Ming]、白毛茶(C. sinensis var. pubilimba Chang)、 
毛叶茶(C. ptilophylla Chang)等。值得注意的是在中 南半岛和南亚还栽培一种特殊类型的茶, 即高棉茶 或柬埔寨茶(Cambod tea), Wight (1962)将其视为大 叶茶的一个亚种[C. assamica ssp. lasiocalyx (Watt) Wight], 其形态特征介于大叶茶和小叶茶之间, 但 这一名称在张宏达先生和闵天禄先生的系统中都 未进行处理。最近Das和Ghosh (2016)对这一类型进 行了分类修订, 将其定为 Camellia sinensis (L.) O. Kuntze var. lasiocalyx (G. Watt) A. P. Das \& C. Ghosh。但是, 基于遗传结构的分析证明这一类型的 茶实际上是小叶茶和大叶茶之间的杂交品种, 并不 是一个自然的分类群(Meegahakumbura et al, 2016; Wambulwa et al, 2016a)。值得注意的是在那些少量 栽培的种类中，大苍茶和大理茶的模式标本就采自 村寨附近的栽培个体，毛叶茶则是近年才开始被有 规模地栽培。除上述类群外, 野外调查中还见到民 间采集多种野生茶树的叶制成茶，但规模都不大， 包括大厂茶(C. tachangensis F. C. Zhang)、厚轴茶( C. crassicolumna Chang) 以及广西茶(C. kwangsiensis Chang)等。近年随着市场上鼓吹大树茶的品质更好, 从野生或半野生乔木型茶树上采集叶片来加工成 茶的现象明显增多，对茶树资源造成了巨大破坏 (Zhao et al, 2014; 李苗苗等, 2015)。因此, 当我们讨 论栽培茶的起源时, 首先需厘清到底讨论的是哪一 类茶，同时也需厘清所涉及的野生茶树到底属于 哪个物种。

\section{栽培茶的起源}

祖先类型、起源地点、起源时间以及驯化历程 是研究栽培作物起源的 4 个关键问题, 解决这些问 题往往需要多个学科共同努力。有关茶起源的研究 很多, 但限于篇幅, 本文仅讨论文献学、语音学、 遗传学和考古学 4 个方面的进展。

\section{1 有关栽培茶起源的文献学证据}

尽管中国存在最丰富的古代茶文献, 然而汉代 以前的相关文献还是很少, 更没有栽培茶在何地何 时起源的记载。众多学者已对这些文献做了全面的 论述(参见姚国坤和程启坤, 1992), 认为秦汉时期涉 及茶的可靠而又明确的记载只有以下4则: 《尔雅》、 司马相如的《凡将篇》、王亭的《僮约》以及杨雄 的《方言》。至于“神农尝百草”发现茶的药用效果目 前还属于传说，《华阳国志 -巴志》提到巴国向周
武王进贡的“茶” 以及《尚书 ・顾命》中的“王三宿, 三 祭, 三咤”中的“咤”是否就是茶也还有待确认。

古代文献常常充满争议, 但以下几个事实应该 是明确无误的: (1) “茶”这一植物或物品在古代汉文 字中存在多种多样的写法, 包括茶(cha, tu)、苦茶、 槚(cha, jia, gu)、茗、荈、蔎(she)、芠、荈诧，但肯 定不写作“茶”, “茶”字出现在唐朝，在陆羽的《茶 经》出版后方广为使用; (2)最早的三条有关茶的可 靠记载都发生在蜀地; (3)在汉字体系中, “茶”和 “槚”这一草一木两种植物最早肯定不是指茶这种植 物，在西汉或更早才开始用来表示茶。正是根据上 述文献以及其他明确记载巴蜀之地有野生乔木型 茶树的古代文献，有学者推测巴蜀之地是栽培茶的 起源地(朱自振, 1982)。我们认为这些文献记载或许 还无法确業地证明上述结论，但无疑可证巴蜀之地 是最早规模化栽培和饮用(食用)茶的地区之一。现 代考古也证实上述文献记载所言非虚，西汉确已有 茶(Lu et al, 2016)，这将在后文论述。

汉以后, 有关茶的记载越来越多, 其中详细记 录了巴蜀是第一个茶生产中心，自三国、两晋至唐， 茶的栽培中心从西向东移, 至宋、元再向东南移动 的过程。对此, 已有学者做过较为全面的综述(见朱 自振, 1992), 这里不再赘述。

\section{2 栽培茶起源和传播的语音学证据}

古代许多族群缺乏文字, 因而记载茶的古老文 献很少, 但所有族群都有语言, 而且不同族群通常 语言不同，即使同一族群也会有不同的方言。因此， 从不同区域的人们如何说茶这一植物或物品的信 息中，可以追溯茶文化的起源、传播与发展，众多 学者已经做出了有益的尝试(高晓山, 1984; 周靖民, 1985；李锦芳, 2005; 薛德炳, 2015)。这不仅涉及茶 本身的使用、栽培和制茶知识的传播，还涉及民族 的迁移、融合等。近代茶在欧洲、非洲等地区的传 播及茶发音的演变为追溯古代茶在国内及附近地 区的传播提供了重要的参考和启示，因为近代的传 播过程有详细的文献记载可以确证。如在中国以外 的地区，特别是几乎包括印度的所有地区，“茶”存 在两类不同的发音: tea类和cha类。前者可从福州、 潮州方言追溯至厦门方言(te/tay), 后者可追溯至广 州一带的方言(cha) (高晓山，1984; 马晓俐，2010), 这是中国最早对外开放的两个重要口岸，显然也是 中国最早向西方输出茶叶的地区。 
那么厦门的te/tay和广州的cha的音又来自何处 呢? 各自独立出现还是存在关联涉及茶在中国的 起源。“cha”的音分布很广, 哪里的人最先说这一音 的呢? 有学者推测最早的cha音来自古代巴人(薛德 炳，2015), 认为巴蜀地区至今有多种发音, 包括 cha、she、 jiameng、chuan cha等，且与古老方国的 “苴” (多音, 发ba, cha等)相关联, 至今川东、渝东的 居民饮浓茶时, 仍有ba chu, ba sha, ba che等语音(薛 德炳, 2015)。

但也存在另一种可能, 这一发音来自南方的其 他族群, 其中之一就是云南南部的孟高棉民族(被 称为北方孟高棉族)。现阶段属于孟高棉语系的族群 主要分布于中南半岛, 在我国云南分布有仾、德昂 (崩龙)和布朗 3 个民族(马曜，1978), 后两个民族被 认为是最早使用和栽培茶的民族之一。这 3 个民族 都没有文字, 其中低族将茶说成cha或la, 布朗族把 茶说成la，德昂族则说成jaju (李锦芳, 2005; 李全敏, 2013; 王仲黎, 2016)。特别值得注意的是后两个民 族的发音和意义, 德昂族中 ja意为祖母和外祖母, 而ju意为眼睛亮了, 传说是茶治好了古代德昂族王 子母亲的眼疾(李全敏, 2013); 而布朗族语言中茶 的发音 $l a^{33}$ (中平调)与普通叶子的发音 $\mathrm{la}^{51}$ (高降调) 很近。这表明德昂族的ja以及布朗族的 $\mathrm{a}^{33}$ (中平调) 的发音很可能并不是来源于茶(cha)的直接转用, 甚 至可能其他地区茶“cha”的发音最早就来自这两个 民族。布朗族的另一个发音似乎支持这样的猜测, 布朗族将茶还用作食材，是布朗族先民的“野菜” 之一, 这种野菜常用作佐料，布朗族称之为“得 责” [ $\left.\mathrm{tr}^{55} \mathrm{tciat}^{31}\right]$, 与其他地区的任何一种有关茶的发 音都不相似, 暗示了这些民族或许是独立获得这些 知识。德昂族与茶的密切联系还可以从该族的史诗 《达古达楞格莱标》得以印证: 在这部长达558行的 史诗中, 德昂族以茶为万物之源, 把茶树当作万物 的始祖, 人类的祖先, 祖祖辈辈都把茶树视作具有 生命、意志和伟大能力的对象而加以崇拜(赵腊林和 陈志鹏, 1981; 周灿和赵燕梅, 2013), 这在使用茶的 各民族中独一无二。尽管上述史诗描绘了德昂族与 茶的密切联系, 但目前还不知道这一史诗产生于何 时、何地, 因而也就不能明确判断德昂族何时与茶 建立如此密切的联系, 相信随着对该史诗的深入研 究, 会得到更为清晰而明确的信息。

我国华南地区一些讲侗台语的民族对茶还有
一些十分不同的称谓，如“过罗”、“拘罗”、“瓜卢” 等，这些发音听起来与“cha”十分不同，但据李锦芳 (2005)研究，它们实际上与茶的早期发音“槚”、“臬 卢” 密切相关, 认为后者就来自古代南方百越(侗台) 语。这样看来, 国内所有茶的发音都存在高度的相 似性和相关性。这一结果暗示了早期茶知识来源的 单一性及茶知识传播的方向。

根据上述信息, 我们虽不能确定是华南(古代 侗台族群)还是云南南部(古代北方孟高棉族等)或 是古代巴蜀中的哪一地最先获得使用和栽培茶的 知识, 但可以断定的是无论哪一个族群最先获得茶 的知识，相互之间肯定存在非常早的交流。现有的 考古发现表明巴蜀之地不仅与长江中下游地区存 在密切的交流，与云南以及中南半岛北部地区也存 在久远和频繁的交流，现在生活于中国南方以及中 南半岛北部的多个民族就是原生活于长江流域的 两个古老族群百誉和百越南迁的直接后裔或混血 后代。如上文所述的云南孟高棉族群(俪、德昂和布 朗), 他们的起源虽还众说纷纭, 但研究表明即使他 们不是誉人的直接后裔, 也肯定受到南迁湩人部落 的影响(何平，2003; 李晓斌等，2007)。从巴蜀至云 南南部的广大地区都分布有多种多样的茶组植物, 只要拥有栽培和使用茶的知识, 有理由相信这些知 识将随族群的迁移而流传, 并在族群迁移中就地取 材当地的野生茶树加以利用。大理茶的栽培很有可 能就是获得茶知识的当地民族独立开展的。如果没 有茶的知识，很难想象大理茶分布地的民族也会将 这一物种发与茶相似的音(如白族将茶发成tso)。

景颇族对茶的发音也是值得研究的，英国人 Robert Bruce于1823年在印度阿萨姆地区得到的茶 树就是当地景颇族所种植 (Taknet, 2002)。景颇族不 是当地的土著民族，该民族的记忆及考证表明他们 来自北方青藏高原的东部地区，几经迁移到达现在 的云南、缅甸和印度东北部。可能早在汉代这一民 族就进入云南境内, 至宋代, 西进的景颇语支系可 能沿独龙江南下到恩梅开江流域与缅语支等汇合， 成为现代景颇族分布的雉形(李怀宇, 2003)。如果 说 这一民族没有在南迁过程中学会利用、栽培茶的知 识是很难令人相信的, 因为他们迁移所经过的地区 早已有大量茶栽培。但景颇族称茶为pha lap (李锦 芳, 2005), 这听起来与cha、tsa等发音差别很大, 为 何如此, 还有待研究。 


\section{3 有关栽培茶起源的遗传学证据}

遗传物质是追溯一个分类群谱系发生最直接 的证据。随着分子标记技术的发展, 自20世纪末, 中国、印度、日本等国的学者利用多种分子标记技 术分析了不同区域、不同栽培茶的遗传多样性和遗 传结构, 本文列举了其中最主要的28项研究(表2)。 这些研究收集的样品来源不同、数量不一、使用的 分子标记也各不相同, 因而结果很难一一比较。尽 管如此, 分析这些研究, 我们至少可以得到如下重 要信息, 有助于更深入地认识茶树的驯化起源和 传播。

(1)在人类作用下，茶品种间的杂交、基因渐渗 以及栽培茶与野生近缘种杂交和渐渗十分普遍。例 如, 高棉茶很可能就来自大叶茶与小叶茶的杂交 (Meegahakumbura et al, 2016); 而印度栽培茶的品 种十分混杂, Raina等(2012)对印度1,644份栽培茶样 品的遗传多样性的研究也表明, 其杂交类型十分丰 富，并且发现遗传类型与基于形态特征的分类型并 不一致, 印度很多栽培茶为印度产大叶茶和中国产 小叶茶之间的杂交品种(Meegahakumbura et al, 2016); 非洲栽培茶的历史不到200年，但其栽培茶 群体中存在多个类型且品种间遗传差异大, 主要包 括来自中国的小叶茶和印度的大叶茶以及它们间 的杂交品种, 且多以大叶茶为母本的 $F_{1}$ 代和回交后 代的杂交品种为主(Wambulwa et al, 2016a, b, 2017); 对大理茶(包括C. irrawadiensis Burua)和中国大叶 茶居群的遗传结构分析则发现大理茶的遗传物质 渗入到大叶茶中, 暗示了大理茶很可能参与了大叶 茶的驯化过程(刘阳等, 2010; 李苗苗等, 2015)。

(2) Meegahakumbura等(2016)利用SSR标记, 通 过分析来自中国和印度的392份茶树种质资源(不仅 包括了大量古茶树和近似野生茶树的样品, 还包括 了两个国家主要产茶区的茶树品种资源)的遗传组 成与结构, 结果表明, 栽培茶树可分为 3 个遗传谱 系, 代表了3种不同的茶树类型, 即小叶茶、中国产 大叶茶(主要产云南南部和西部)和印度产大叶茶, 后两者虽同属大叶茶, 但代表不同的遗传谱系, 进 而推测小叶茶、中国大叶茶和印度大叶茶很可能各 自独立起源, 中国大叶茶很可能起源于云南西南 (南部及西部地区)及相邻区域(如缅甸), 而印度大 叶茶则可能起源于印度阿萨姆地区。对叶绿体DNA 片段的分析也表明印度阿萨姆地区确实栽培着一
类谱系上与中国大叶茶十分不同的茶树(Meegahakumbura, 2016)。

(3)悠久的茶树栽培区存在众多地域性类型, 这些地方品种的遗传组成与其他区域的品种十分 不同。除了上文所述的中南半岛的高棉茶和印度的 大叶茶外, 日本的栽培茶也十分不同, Taniguchi等 (2014)利用SSR标记分析了日本从亚洲各国范围内 收集的788份茶种质资源的遗传组成，结果发现可 以将这些茶分为 3 类。其中, 日本栽培的品系构成 独立的一类, 但遗传多样性低, 来自其他区域的茶 构成另外两类, 分别对应大叶茶和小叶茶; 中南半 岛各国及孟加拉、斯里兰卡以及印度的部分品种似 乎属于前者，而中国、韩国、印度的很多品种属于 小叶茶。日本的栽培茶叶无疑最早是从中国引入的 (Matsumoto et al, 2002), 但上述结果表明长期的人 工选择使日本的栽培茶与中国小叶茶发生了遗传 分化，两者间的遗传差异甚至比大叶茶与小叶茶的 遗传差异还要大。而根据Katoh等(2003)的分析, 缅 甸栽培的茶树遗传类型也十分丰富，不仅包括大叶 茶、小叶茶, 还有些来源于大理茶(包括C. irrawadiensis Burua)等。

(4)中国的栽培茶拥有十分丰富的遗传多样性 和栽培类型，除了上文所述的小叶茶、大叶茶外， 在云南西南地区，长期以来当地居民也栽培大理 茶、大苍茶和德宏茶(Zhao et al, 2014)。Yao等(2012) 分析了采自中国各茶区的450份茶树样品的遗传结 构, 这是到目前为止对中国栽培茶遗传多样性最全 面的研究, 不仅包括的样品多和广(包括331份采自 中国各茶区的地方品种，87份引入品种以及大理 茶、大厂茶、厚轴茶、白毛茶等32个野生、半野生 类型), 而且所检测的EST-SSR位点多达96个。结果 发现: (1)地域性的分化十分明显, 从遗传结构上看 可以分成明确的 5 类, 湖南以东(包括湖南)的长江下 游各省以及福建的栽培茶遗传上高度一致, 分为一 类，广东与广西、贵州与重庆、湖北与四川相邻两 省的栽培茶品种除少数个体外, 各有十分相似的遗 传组成而分别分成3类，云南的地方品种独成一类; (2)云南、贵州、广西三省的茶有较高的遗传多样 性; (3)按遗传组成区分的5类茶, 并不与分类学上 的种或亚种对应，小叶茶和大叶茶与野生种类的关 系并未得出结论，尽管湖北、四川、重庆、贵州4 省栽种的地方品种都属于小叶茶, 但其遗传组成上 


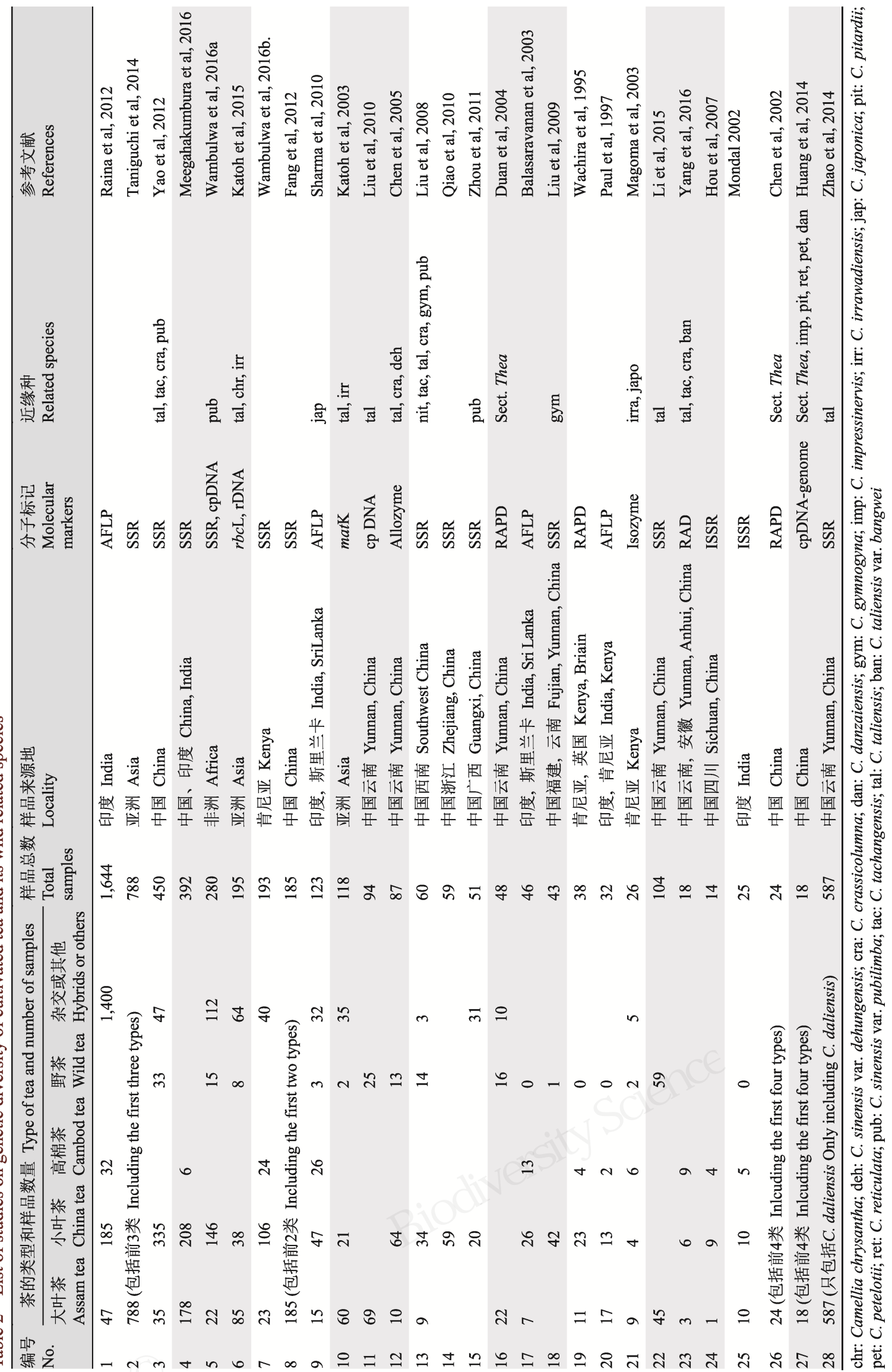


与长江下游的小叶茶并不一致(Yao et al, 2012)。

(5)利用RAD-seq技术，Yang等(2016)分析了包 括大叶茶、小叶茶、大理茶、厚轴茶等18个茶组植 物个体的遗传关系, 研究材料中包括从形态特征上 被认为是介于野生与栽培的中间过渡类型的邦威 大树茶。结果表明邦威个体确实不同于大叶茶与小 叶茶, 也不同于大理茶等其他种类, 是前两类栽培 茶最近的姐妹群, 这一结果支持栽培的大叶茶和小 叶茶都来自云南南部的假说, 但还需要更多的材料 和数据进行证实(Yang et al, 2016)。

实际上, 表2所示的研究结果彼此之间的不一 致更为突出, 限于篇幅不能一一讨论。这里只举一 个突出的例子。Huang等(2014)测定了13种(含亚种) 的叶绿体基因组序列, 根据其结果得出如下结论: (1)大叶茶和小叶茶不仅是独立的起源, 而且是完全 不同的种, 前者的祖先与毛肋茶是姐妹种, 后者则 与膜叶茶(C. leptophylla S. Y. Liang et Chang)关系密 切, 而白毛茶也为独立的种; (2)从叶绿体谱系上看 大理茶甚至不属于茶组。这一结果无疑是令人吃惊 的, 从形态特征上看, 大理茶无疑是茶组植物, 毛 肋茶、膜叶茶与小叶茶也区别明显, 特别是毛肋茶 因有离生的花柱和宿存的小苞片甚至被归入离荵 茶组(闵天禄, 2000)。上述结果与根据等位酶和部分 叶绿体基因进行的群体遗传分析获得的结果也相 矛盾, 例如有研究表明大理茶与大叶茶十分相似, 谱系上甚至不能分开(Chen et al, 2005; 刘阳等, 2010; 李苗苗等, 2015) (表2)。

根据DNA信息研究茶组植物的遗传多样性及 分类系统, 结果为什么会有如此大的差异? 一方面, 我们认为利用不同的分子标记可能会带来不同的 结果: 早期使用RAPD与ISSR进行研究, 其结果的 重复性可能会存在问题; 利用叶绿体DNA (cpDNA, 母性遗传)与利用SSR位点(绝大多数位于核基因组 内)得到的结果也会出现差异; 而同样是利用SSR位 点, 如果不是利用严格遵从Hardy-Weinberg平衡的 SSR位点来分析, 不同的SSR位点也会得到不同的 结果。另一方面, 我们认为更重要的原因在于不同 研究使用的样品的准确性、采集范围及数量存在较 大差异(表2)。实际工作中发现, 即使按照闵天禄分 类系统(闵天禄, 2000), 整个茶组植物种间差异都很 小, 不容易识别, 而且无论是种间还是同种不同品 种间杂交亲和性都很高(Raina et al, 2012), 正如表1
所述，人类栽培的茶树包括多个种，广泛的引种给 原来分布区不重叠的种或变种提供了众多的杂交 机会, 加上人工杂交育种等活动, 使得目前栽培茶 的杂交类型十分常见, 这给样品的确定带来困难, 那些形态上看起来十分相似的品种遗传组成上很 可能明显不同(Raina et al, 2012), 可想而知在取样 的范围和数量有限的情况下, 如果样品的准确性再 存在问题, 结果必然会发生偏离。

\section{4 有关栽培茶起源的考古学证据}

对于栽培作物的起源, 考古发掘的遗物是最直 接的证据。有关栽培茶的化石和遗存发现很少, 到 目前为止，明确或较为明确的考古证据仅有 2 例 最 为明确的考古发现来自西汉西安古墓和西藏阿里 古墓的随葬品。Lu等(2016)在上述两个埋藏中发现 了显然是加工过的茶, 特别是西安古墓中的茶为幼 芽所制，与现代茶十分类似。这一发现不仅证明早 在2,100多年前, 在西汉的中心地带已有饮茶的习 惯, 而且远在西藏阿里的人们也在使用茶叶, 证实 司马相如等对蜀地有关茶的记载应该是可靠的。这 一发现使我们有理由推断南方栽培茶及饮茶习惯 一定比2,100年前早得多。这些发现还引发了十分有 趣的问题: 茶是如何传到偏远而海拔很高(平均 $4,000 \mathrm{~m}$ 以上)的阿里呢? 是从张寒刚开通的丝绸之 路传播还是通过传说中更早的身毒(印度)之路流传 呢? 如果是后者, 茶在印度的流传就要比现在人们 的认识早得多。

另一项有关栽培茶起源的发现出自新石器时 代的浙江余姚田螺山遗址, 考古学家们在这一古村 落距今约6,000年前的堆积层中发现多个保存完好、 疑似山茶的根, 通过木材解剖断定这些根是山茶属 植物的根(浙江省文物考古研究所, 2011; 铃木三郎 等, 2011), 并通过分析比较遗存根及分布于浙江的 多个山茶属植物根的茶氨酸含量, 推测这些遗存的 根就属于茶这一物种 (虞富莲, 2010; 程启坤, 2016)。根据这些根靠近干栏式建筑的一些带垫板 柱坑并生活于人工挖掘的熟土浅坑内, 考古学家们 断定这些根应为人工栽培而非野生。尽管上述植物 根是人工栽培还是野生遗留依然存在争议(竺济法, 2015), 而且也不知道当时人们是如何利用它们的, 但这一发现还是暗示, 即使今天没有野生茶组植物 分布, 这一区域也可能是栽培茶的起源地。如果这 一结果被确认是真的，那将引出一系列有趣的问 
题。从遗传多样性的研究来看, 现代长江下游各省, 包括福建等地栽培的茶树品种无疑都是西部或西 南部传播过来的结果(Yao et al, 2012), 田螺山悠久 的栽培驯化活动为什么没有像栽培水稻一样在这 一区域流传下来? 历史上存在百越诸族多次南迁 的事件, 是否这一区域的古人南迁时将有关茶的知 识传播到南方? 这些问题还有待于更多的研究。

\section{未来的工作展望}

正如前文所述, 任何一种栽培植物的起源都涉 及祖先类型、起源地点、起源时间以及驯化历程等 问题。就栽培茶的起源来说, 尽管已经取得了可喜 的成果, 提出了多个有意义的假说, 这些假说虽彼 此间存在矛盾却各有证据支持。但严格说来, 上述 4 个问题没有一个得到明白无误的证明, 还需要更多 的证据。笔者看来, 未来的工作应该特别加强如下 方面的研究:

(1)茶组植物的分类和谱系重建。所有栽培植物 追根溯源都来自野生种, 尽管我们探求的问题是栽 培茶树甚至只是 $C$. sinensis (L.) O. Kuntze中栽培类 型的起源, 但也依赖于整个茶组植物清晰的分类界 定及明确的谱系关系。正如上文所述(表1), 栽培茶 的野生近缘种分布广泛且种类众多, 而且物种的界 定仍存在很大争议。例如, 闵天禄(2010)的系统将所 有大规模栽培的茶树类型如C. arborescens Chang \& F. L. Yu、C. assamica (Mast.) Chang以及C. dehungensis Chang \& B. H. Chen等都归入C. sinensis (L.) O. Kuntze这一名称之下, 而张宏达和任善湘(1998) 则将栽培的茶划分为至少 6 个种：包括：茶 [C. sinensis (L.) Kuntze]、普洱茶[C. assamica (Mast.) Chang]、狭叶茶(C. angustifolia Chang)、多蕶茶(C. multisepala Chang)、大树茶(C. arborescens Chang et $\mathrm{Yu}$ )和细萝茶(C. parvisepala Chang)。前两个种又分 别各包括3个变种。上述两个系统的分类都只根据 部分形态特征进行, 而很多形态特征的变异常常不 是间断的, 这给分类群的识别带来困难。在我们厘 清物种的界限问题之前, 只选其中一个种来研究很 难获得正确的结论。

另外一个问题更为突出, 山茶属植物种间杂交 比较普遍, 同组的种类更容易杂交, 由于栽培茶树 与其野生近缘种(茶组物种)通常同域分布(特别在 我国西南地区), 而在我国茶的栽培历史又是如此
悠久, 从野生种类向栽培类型的基因渗入是可以预 见的(如大理茶的基因就可能渗入到大叶茶之中, 刘阳等, 2010; 李苗苗等, 2015), 而人为有意的杂交 就更为常见(Raina et al, 2012), 这导致茶的遗传来 源复杂, 形态变异多样, 因此基于形态的分类非常 困难。另一方面，从栽培向野生的回归也很常见， 一些被界定为野生型的古茶树可能是从茶园中逃 逸到野外, 而并非真正的野生茶树, 这给研究茶树 栽培类型的起源带来困难。因此，要揭示这一问题 需要将更多的种类考虑进来一起研究。目前大多数 研究还只是包括栽培品种(表2), 没有或很少有野生 近缘种的材料, 因而还不能进行真正的谱系分析。 已有一些工作注意到这一问题并做了十分有益的 尝试(陈亮等, 2002; Yao et al, 2012; Huang et al, 2014; Yang et al, 2016), 但涉及野生近缘种的类型 和数量太少或获得的分子信息有限, 结论的可靠性 还需确认。鉴于茶组植物种边界的模糊性以及栽培 茶起源问题的复杂性，未来的研究应该将茶组植物 作为一个整体严格按谱系地理学要求取样, 构建茶 组植物的谱系发生关系, 在此基础上再讨论栽培茶 的起源。

(2)构建谱系的分子标记的选择。Avise (2000) 指出真实的谱系发生应该不仅需要来自细胞质基 因组的信息，也需要来自核基因组的信息，对于像 茶组植物这样容易杂交的植物来说更是如此。以往 的研究发现山茶属植物的叶绿体基因组片段与其 他类群相比变异位点很少，常用的片段(如 matK, $r b c \mathrm{~L}$ 等)难以用于研究山茶属物种的谱系发生, 但 近来随着众多山茶属植物(包括多个茶组植物)的叶 绿体基因组被测定, 发现了一些变异较快的DNA片 段。如Wambulwa等(2016a)利用3个进化速率较快的 叶绿体DNA片段对非洲8个国家的栽培茶开展了研 究，结果促进了对非洲栽培茶来源的认识。同样, 山茶属植物的基因组数据也有报道(Xia et al, 2017), 而转录组数据就更多, 这提供了机会䇥选单拷贝或 低拷贝的核基因来进行双亲谱系关系的研究。SSR 位点被广泛用来研究茶的遗传多样性和遗传结构 (表2), 但若使用非中性的SSR位点，则可能会使结 果偏离真实的历史(Taniguchi et al, 2014), 而且检测 的位点也常常有限, 不能反映整个基因组的分化。 此外, 众多SSR位点变化十分快, 用来揭示现阶段 群体的遗传结果十分有效, 但要根据其结果来推测 
其历史就十分困难和不可靠。基于第二代测序技术 开发的新分子标记技术, 如RAD、重测序等, 已经 被广泛用于其他栽培作物的研究(Huang et al, 2012; Marcussen et al, 2014)。Yang等(2016)使用RAD技术 对18份栽培茶树和野生近缘种进行了研究, 对小叶 茶与大茶树的亲缘关系及与茶叶品质相关的基因 进行了分析, 获得重要的结果。然而, 由于使用的 材料十分有限, 这一方法的应用及其所得出的结论 还有待进一步验证，而且目前这一方法几乎还没有 用于栽培茶的群体遗传研究。相信随着这些技术的 应用, 将会极大地推动我们对栽培茶进化历史的认 识, 特别是随着对更多茶及近缘种全基因组序列的 测定，栽培茶驯化种发生的谜团将会逐步被揭开。

(3)语音学及民族植物学研究。语言是人类文明 在时空中传播最为重要的工具。尽管不同地区、不 同民族对茶这一物品发音的相似性和相关性暗示 了茶文化起源的单一性, 然而, 很多研究还只是基 于推测, 未来需要扩大至与茶相关的更多词汇, 使 用更为科学的方式来追溯相关语音的变化, 特别是 应该结合民族植物学的研究。目前有关茶的民族植 物学的研究还非常有限(陈进, 2003; 李捕罕和秦莹, 2015), 且缺乏更大范围内和更多民族的比较。语音 学和民族植物学的整合比较研究不仅能帮助我们 揭开茶文化的起源、传播及演变, 也将有助于我们 认识茶的栽培类型的起源。例如, 在我国云南及附 近地区的一些少数民族还保留多种多样的利用茶 树的方式, 而在越南南部的一些山区至今还保留最 原始的喝茶方式, 即从茶树上直接采取新鲜枝叶煮 水即喝, 这些信息对于研究茶文化的传播都具有重 要的意义。近年有关栽培的香蕉起源和传播的研究 方法值得借鉴(Perrier et al, 2011), 特别是有关语音 学的部分。该文作者收集了 1,100 个与香蕉相关的词 汇, 利用标准的语言分析比较方法(Joseph \& Janda, 2003), 构建词汇的邻接树 (neighbor-joining tree), 获得了与香蕉相关的词汇语音变化的信息。与茶相 关的词汇十分丰富, 而且地域性很强, 值得用相似 的方法深入研究。

此外, 越来越多的证据表明, 早在3,000-4,000 年前的三星堆文化时期, 巴蜀地区的文明不仅与长 江中下游的文明密切相关, 而且与中南半岛甚至印 度都存在远比以往认识要密切得多的联系, 如越南 北部发现与三星堆高度相似的牙璋, 而三星堆则发
现了众多海贝等南海甚至印度洋的物品(段渝, 1993, 2015; 张弘, 2009; 彭长林, 2015)。对于后一条路线, 云南就是最重要的通道, 因此, 在考虑茶文化的传 播时，必须基于民族的迁移以及不同地区漫长的交 往历史这一重要的背景。

(4)缅甸、越南、印度东北部的野生茶组植物。 中南半岛的许多区域(包括越南、老挝、缅甸等的北 部地区) 以至印度东北部的阿萨姆地区也有野生茶 组植物分布, 但缺乏详细的调查。已有研究中来自 上述地区的野生样品很少, 而且分类学归属也有待 确认。根据目前的研究, 我们可以看出这些地区的 样品对于阐明栽培茶的起源十分关键。例如, 有研 究推测小叶茶、印度大叶茶、中国大叶茶3类栽培 茶很可能独立起源(Meegahakumbura et al, 2016), 这无疑需要更多的野生茶树样品来进一步确认; 而 根据叶绿体全基因组的研究, 小叶茶和德宏茶的祖 先与膜叶茶最近, 大叶茶的祖先则与毛肋茶构成姐 妹群(Huang et al, 2014), 前一个野生种目前只在广 西、越南交界的很小区域有采集记录，在越南的分 布一无所知, 而后一个野生种只在越南的巴维山有 记录, 国内所获样品的可靠性有待确认，需要更多 的样品才有说服力。因此, 无论从发现新的野生茶 组植物资源的角度, 还是从研究栽培茶起源的角度 都需要对这些地区开展更为深入的调查。

(5)近万年以来的全球气候变化与茶分布区的 波动。在化石缺乏的情况下, 常常根据野生近缘种 及栽培类型的谱系地理关系来推断栽培作物的起 源地。但这样推理的前提条件是在栽培作物起源后 野生近缘种的分布格局没有重大变化，否则很可能 得出错误的结论。然而, 上述前提条件常常是不成 立的，越来越多的研究表明近 1 万年来，由于全球 气候的波动及人类活动的影响, 许多动植物的分布 区都发生过重大变化(竺可桢，1972; 黄璜等，1998; 文焕然，2006)。最典型的例子就是野生稻(Oryza rufipogon)的分布, 大量化石证明在6,000-7,000年 前, 野生稻分布至黄河流域, 长江下游地区很可能 是栽培水稻的起源地, 但现在野生稻在这一地区已 经消失殆尽(黄璜等, 1998), 根据现存群体来推断栽 培稻的起源地必然会引发争议(Fuller et al, 2009; Huang et al, 2012)。茶组植物的分布也发生了变化, 唐代的陆羽在《茶经》中曾记载“茶者, 南方之嘉木, 一尺、二尺, 遁至数十尺, 其巴山峡川, 有两人合抱 
者，伐而捜之”，现阶段在此区域两人合抱的野生 大茶树已十分罕见。而长江下游地区尤其是在浙江 余姚，已经没有野生茶树了，在田螺山遗址发现山 茶植物的根, 说明6,000多年以前, 这里完全有可能 分布有野生茶树。实际上, 近在 20 世纪 40 年代, 在 山东省还发现一株粗有三抱、高约5丈的大茶树(陈 兴琰等, 1979), 尽管不知道这一孤立的乔木型茶树 的来源, 但至少说明在近代大茶树还能在那里生 存。鉴于上述原因, 未来在研究栽培茶的起源时, 必须考虑近万年来野生茶分布区的可能变化, 还需 考虑在漫长栽培历史过程中各地区栽培品种的更 替对区域遗传多样性造成的影响。

综上所述, 中国长江流域及以南地区分布有众 多茶组植物, 包括各类栽培茶的野生近缘种; 南方 各民族语言中“茶”发音的相似性及相关性暗示了茶 知识起源的单一性, 最可能的地区在古代的巴蜀之 地或云南南部，而遗传结构上的特征揭示出栽培茶 的起源涉及茶组植物的多个物种, 即使就C. sinensis (L.) O. Kuntze (包括多个亚种)这一物种的栽培 类型而言, 也可能有多个起源; 历史文献显示了茶 文化在长江流域从西向东的传播和发展, 遗传信息 也揭示出从古巴蜀之地至长江中下游遗传多样性 的减少，但考古发现却指出很可能最早的栽培茶就 出现在长江下游; 在茶的栽培品种、特别是在茶知 识的传播过程中, 当地野生茶组植物的基因渗入至 栽培类型中，或直接用当地野生资源培育不同的栽 培类型以及人为的杂交等导致遗传上的复杂性。未 来的研究需要从整个茶组植物出发, 利用文化、遗 传、地质环境变化、考古等多种方法提供明确的 证据。

致谢：感谢陶乃奇帮助整理参考文献。

\section{参考文献}

Avise JC (2000) Phylogeography: The History and Formation of Species. Harvard University Press, Cambridge.

Baildon S (1877) Tea in Assam: A Pamphlet on the Origin, Culture, and Manufacture of Tea in Assam. W Newman \& Co Ltd., Calcutta, India.

Balasaravanan T, Pius PK, Kumar RR, Muraleedharan N, Shasany AK (2003) Genetic diversity among south Indian tea germplasm (Camellia sinensis, C. assamica and $C$ assamica spp. lasiocalyx) using AFLP markers. Plant Science,
$165,365-372$

Chang HT (1981) Systematic study of the genus Camellia. Journal of Sun Yatsen University (Natural Science Edition) Forum, (1), pp. 108-125. Journal of Sun Yatsen University Editorial Office, Guangzhou. (in Chinese) [张宏达 (1981) 山茶属植物的系统研究. 中山大学学报(自然科学)论从, (1), 108-125页. 中山大学学报编辑部, 广州.]

Chang HT, Ren SX (1998) Flora Reipublicae Popularis Sinicae, Tomus 49(3), Theaceae (1): Theoideae. Science Press, Beijing. (in Chinese) [张宏达, 任善湘 (1998) 中国 植物志第四十九卷第三分册, 山茶科(一): 山茶亚科.. 科 学出版社, 北京.]

Chen J (2003) Genetic Diversity and Ethnobotany of Cultivated Tea and Wild Relatives in Yunnan Province of China. PhD dissertation, Kunming Institute of Botany, Chinese Academy of Sciences, Kunming. (in Chinese with English abstract) [陈进 (2003) 中国云南栽培茶及野生近缘种的遗 传多样性与民族植物学研究. 博士学位论文, 中国科学 院昆明植物研究所, 昆明.]

Chen J, Pei SJ (2003) Studies on the origin of tea cultivation. Acta Botanica Yunnanica, Suppl. XIV, 33-40. (in Chinese with English abstract) [陈进, 裴盛基 (2003) 茶树栽培起 源的探讨. 云南植物研究，增刊 XIV, 33-40.]

Chen J, Wang PS, Xia YM, Xu M, Pei SJ (2005) Genetic diversity and differentiation of Camellia sinensis L. (cultivated tea) and its wild relatives in Yunnan Province of China, revealed by morphology, biochemistry and allozyme studies. Genetic Resources and Crop Evolution, 52, 41-52.

Chen L, Yamaguchi S, Wang PS, Xu M, Song WX, Tong QQ (2002) Genetic polymorphism and molecular phylogeny analysis of section Thea based on RAPD markers. Journal of Tea Science, 22, 19-24. (in Chinese with English abstract) [陈亮, 山口聪, 王平盛, 许玫, 宋维希, 童启庆 (2002b) 利用RAPD进行茶组植物遗传多样性和分子系统学分析, 茶叶科学, 22, 19-24.]

Chen XY, Chen GB, Zhang FC, Liu ZS, Zhao XR, Chen ZG, Yang WS, Zhan ZJ (1979) Big tea tree in China. Journal of Hunan Agricultural College, (3), 55-63. (in Chinese) [陈兴 琰, 陈国本, 张芳赐, 刘祖生, 赵学仁, 陈震古, 杨维时, 詹梓金 (1979) 我国的大茶树. 湖南农学院学报, (3), 55-63.]

Chen ZM (1992) China Tea Classic, pp. 1-29. Shanghai Culture Press, Shanghai. (in Chinese) [陈宗檚 (1992) 中国茶 经, 1-29页. 上海文化出版社, 上海.]

Cheng QK (2016) Understanding of 6000-year-old human planted tea tree roots discovered in Tianluoshan Site. China Tea, (2), 30-33. (in Chinese) [程启坤 (2016) 对田螺山遗 址中发现六千年前人为种植的茶树根的认识. 中国茶叶, (2), 30-33.]

Chinese Teaman Friendship Association, China Tea Science Society (1994) Ancient Tea Trees in China, pp. 6-118. Shanghai Culture Press, Shanghai. (in Chinese) [中华茶人 联谊会, 中国茶叶学会 (1994) 中国古茶树, 6-118页.上 
海文化出版社, 上海.]

Das AP, Ghosh C (2016) Camellia sinensis var. lasiocalyx (G. Watt) A. P. Das \& C. Ghosh: New combination name for the Cambod variety of tea. Pleione, 10, 167-168.

Doebley JF, Gaut BS, Smith BD (2006) The molecular genetics of crop domestication. Cell, 127, 1309-1321.

Duan HX, Shao WF, Wang PS, Xu M, Pang RH, Zhang YP, Cui WR (2004) Study on the genetic diversity of peculiar tea germplasm resource in Yunnan by RAPD. Journal of Yunnan Agricultural University, 19, 246-254. (in Chinese with English abstract) [段红星, 邵宛芳, 王平盛, 许玫, 庞瑞 华, 张亚萍, 崔文锐 (2004) 云南特有茶树种质资源遗传 多样性的RAPD研究. 云南农业大学学报, 19, 246-254.]

Duan Y (1993) Relationships between Shang Dynasty bronze culture of western Sichuan plain in the upper reaches of Yangtze River and North China and world civilizations. Southeast Culture, (2), 1-22. (in Chinese) [段渝 (1993) 论 商代长江上游川西平原青铜文化与华北和世界文明的关 系. 东南文化, (2), 1-22.]

Duan Y (2015) Southern Silk Roads: China-India traffic and culture corridor. Thinking, 41(6), 91-97. (in Chinese) [段渝 (2015) 南方丝绸之路: 中-印交通与文化走廊. 思想战 线, 41(6), 91-97.]

Fang W, Cheng H, Duan Y, Jiang X, Li X (2012) Genetic diversity and relationship of clonal tea (Camellia sinensis) cultivars in China as revealed by SSR markers. Plant Systematics and Evolution, 298, 469-483.

Fuller DQ, Qin L, Zheng YF, Zhao ZJ, Chen XG, Hosoya LA, Sun GP (2009) The domestication process and domestication rate in rice: Spikelet bases from the lower Yangtze. Science, 323, 1607-1610.

Gao XS (1984) Investigations on the origin of tea and tea drinking according to names and voices of tea. China Tea, (4), 34-35. (in Chinese) [高晓山 (1984) 从茶的名称和语 音探讨茶和饮茶源流. 中国茶叶, (4), 34-35.]

Guo YA (1990) Preliminary investigations on wild tea trees in Hainan Island. Guangdong Tea, (2), 36-40. (in Chinese) [郭 远安 (1990) 海南岛野生茶树初步调查. 广东茶业, (2), 36-40.]

Hancock JF (2012) Plant Evolution and the Origin of Crop Species, 3rd edn. CABI Publishing, Cambridge.

He P (2003) On the origin of ethnic groups speaking Austronesian languages and their historical relationship with the ethnic groups in South China. Journal of Yunnan University for Nationalities (Social Sciences), 20(5), 45-48. (in Chinese with English abstract) [何平 (2003) 南岛语民族的起源及 其与中国南方民族的历史关系. 云南民族学院学报(哲学 社会科学版), 20(5), 45-48.]

He QY, Wang PS, Jiang HB, Wu G (2009) Investigation on wild tea resources in some areas of Yunnan Province. Modern Agricultural Science and Technology, (24), 80-81. (in Chinese with English abstract) [何青元, 王平盛, 蒋会兵, 伍岗 (2009) 云南部分地区野生茶树资源调查研究. 现
代农业科技, (24), 80-81.]

Hou YJ, He Q, Li PW, Liang GL, Peng P, Deng M (2007) Genetic diversity of tea camellias germplasm by ISSR molecular marker. Southwest China Journal of Agricultural Science, 20 462-465. (in Chinese with English abstract) [侯渝 嘉, 何桥, 李品武, 梁国鲁, 彭萍, 邓敏 (2007) 应用 ISSR分子标记研究茶树种质资源遗传多样性. 西南农业 学报, 20, 462-465.]

Huang H, Liao XL, Wang SM, Huang GQ (1998) Process and driving forces of adverse separation of the distributing area of wild rice and rice (O. sativa. L) during past 2000 years. I. Relationship between the distribution area of wild rice and rice (O. sativa $\mathrm{L}$ ) and population distribution in ancient and modern times. Acta Ecologica Sinica, 18, 119-126. (in Chinese with English abstract) [黄璜, 廖晓兰, 王思明, 黄国 勤 (1998) 2000年间野生稻和栽培稻(O. sativa. L)分布区 逆向分离的过程及动力. I. 古今野生稻和栽培稻 $(O . s a-$ tiva $\mathrm{L})$ 的分布与人口分布的关系. 生态学报, 18 , 119-126.]

Huang H, Shi C, Liu Y, Mao SY, Gao LZ (2014) Thirteen Camellia chloroplast genome sequences determined by highthroughput sequencing: Genome structure and phylogenetic relationships. BMC Evolutionary Biology, 14, 151-168.

Huang X, Kurata N, Wei X, Wang ZX, Wang A, Zhao Q, Zhao Y, Liu K, Lu H, Li W, Guo Y, Lu Y, Zhou C, Fan D, Weng Q, Zhu C, Huang T, Zhang L, Wang Y, Feng L, Furuumi H, Kubo T, Miyabayashi T, Yuan X, Xu Q, Dong G, Zhan Q, Li C, Fujiyama A, Toyoda A, Lu T, Feng Q, Qian Q, Li J, Han B (2012) A map of rice genome variation reveals the origin of cultivated rice. Nature, 490, 497-501.

Joseph BD, Janda RD (2003) Handbook of Historical Linguistics. Blackwell, London.

Katoh Y, Katoh M, Takeda Y, Omori M (2003) Genetic diversity within cultivated teas based on nucleotide sequence comparison of ribosomal RNA maturase in chloroplast DNA. Euphytica, 134, 287-295.

Katoh Y, Katoh M, Omori M (2015) Identification of teas cultivated in Eastern, Southeastern and Southern Asia based on nucleotide sequence comparison of ribulose 1,5-bisphosphate carboxylase large-subunit of chloroplast DNA and $18 \mathrm{~S}$ ribosomal RNA of nuclear DNA. Food Science and Technology Research, 21, 381-389.

Li CH, Qin Y (2015) Investigation on the De'ang nationality acid tea from the perspective of the anthropology of science and technology. Journal of Yunnan Agricultural University (Social Science), 9(1), 116-122. (in Chinese with English abstract) [李永罕, 秦莹 (2015) 德昂族酸茶的科技人类 学考察. 云南农业大学学报(社会科学), 9(1), 116-122.]

Li HY (2003) The influences of migration on the social development of the Jingpo ethnic group. Journal of Baoshan Teachers' College, 22(1), 16-19. (in Chinese with English abstract) [李怀宇 (2003) 试论迁徙对景颇族社会发展的 影响. 保山师专学报, 22(1), 16-19.] 
Li JF (2005) Etymological studies on Jia and Gaolu, the early words for tea in Chinese. Research in Ancient Chinese Language, (3), 75-80. (in Chinese) [李锦芳 (2005) 茶称 “槚”、“墓卢”语源考. 古汉语研究, (3), 75-80.]

Li MM, Meegahakumbura MK, Yan LJ, Liu J, Gao LM (2015) Genetic involvement of Camellia taliensis in the domestication of Camellia sinensis var. assamica (Assamica Tea) revealed by nuclear microsatellite markers. Plant Diversity and Resources, 37, 29-37. [李苗苗, Meegahakumbura MK, 严丽君, 刘杰, 高连明 (2015) 核基因组微卫星标记揭示 大理茶参与了普洱茶的驯化过程. 植物分类与资源学报, 37, 29-37.]

Li QM (2013) Linguistic collection and the tea world of the De'ang ethnic group. Journal of Guangxi University for Nationalities (Philosophy and Social Science Edition), (2), 102-106. (in Chinese with English abstract) [李全敏 (2013) 语言采集与德昂族的茶叶世界. 广西民族大学学报(哲学 社会科学版), (2), 102-106.]

Li XB, Long XY, Duan LB (2007) Ancient Yunnan's ethnic relations centered on the $\mathrm{Pu}$ and the Menggaomian ethnic people-also a multi-disciplinary study in relation to ethnic genes. Academic Exploration, (4), 104-111. (in Chinese with English abstract) [李晓斌, 龙晓燕, 段丽波 (2007) 以誉人、孟高棉民族为中心的云南古代族际关系考释 一结合少数民族遗传基因的多学科研究. 学术探索, (4), 104-111.]

Li YL, Zhang L, Yang XB, Li DH, Zhang K, Wu TT (2017) Study on spatial distribution and population dynamics of wild Tea in Hainan Island. Forest Resources Management, (2), 81-87. (in Chinese with English abstract) [李苑菱, 张 丽, 杨小波, 李东海, 张凯, 吴庭天 (2017) 海南岛野生 茶树空间分布及种群动态研究. 林业资源管理，(2), 81-87.]

Liu Y, Yang SX, Gao LZ (2010) Comparative study on the chloroplast RPL32-TRNL nucleotide variation within and genetic differentiation among ancient tea plantations of $\mathrm{Ca}$ mellia sinensis var. assamica and C. taliensis (Theaceae) from Yunnan, China. Acta Botanica Yunnanica, 32, 427-434. (in Chinese with English abstract) [刘阳, 杨世雄, 高立志 (2010) 云南古茶园栽培大叶茶和大理茶群体的 叶绿体RPL32-TRNL核苷酸变异和遗传分化. 云南植物 研究, 32, 427-434.]

Liu Z, Wang XC, Zhao LP, Yao MZ, Wang PS, Xu M, Tang YC, Chen L (2008) Genetic diversity and relationship analysis of tea germplasms originated from south western China based on EST-SSR. Molecular Plant Breeding, 6(1), 100-110. (in Chinese with English abstract) [刘振, 王新超, 赵丽萍, 姚明哲, 王平盛, 许玫, 唐一春, 陈亮 (2008) 基于EST-SSR的西南茶区茶树资源遗传多样性和亲缘关 系分析. 分子植物育种, 6(1), 100-110.]

Liu Z, Yao MZ, Wang XC, Chen L (2009) Analysis of genetic diversity and relationship of tea germplasms originated from Fujian Province based on EST-SSR markers. Scientia Agri- cultura Sinica, 42, 1720-1727. (in Chinese with English abstract) [刘振, 姚明哲, 王新超, 陈亮 (2009) 基于 EST-SSR的福建地区茶树资源遗传多样性和亲缘关系. 中国农业科学, 42, 1720-1727.]

Lu H, Zhang J, Yang Y, Yang X, Xu B, Yang W, Tong T, Jin S, Shen C, Rao H, Li X, Lu H, Fuller DQ, Wang L, Wang C, Xu D, Wu N (2016) Earliest tea as evidence for one branch of the Silk Road across the Tibetan Plateau. Scientific Reports, 6, 1-6.

Ma Y (1978) Brief ancient histories of nationalities in Yunnan. People’s Publishing Press of Yunnan, Kunming. [马曜 (1978) 云南各族古代史略. 云南人民出版社, 昆明.]

Ma XL (2010) A glimpse of China tea appellation, pronunciation and spelling in linguistics. China Tea, (3), 38-40. (in Chinese) [马晓俐 (2010) 语言学中的中国茶称谓、发音及 拼写之管窥. 中国茶叶, (3), 38-40.]

Magoma GN, Wachira FN, Imbuga MO, Agong SG (2003) Biochemical differentiation in Camellia sinensis and its wild relatives as revealed by isozyme and catechin patterns. Biochemical Systematics and Ecology, 31, 995-1010.

Marcussen T, Sandve SR, Heier L, Spannagl M, Pfeifer M, The International Wheat Genome Sequencing Consortium, Jakobsen KS, Wulff BBH, Steuernagel B, Mayer KFX, Olsen OA (2014) Ancient hybridizations among the ancestral genomes of bread wheat. Science, 345, 1250092.

Matsumoto S, Kiriiwa Y, Takeda Y (2002) Differentiation of Japanese green tea cultivars as revealed by RFLP analysis of phenylalanine ammonia-lyase DNA. Theoretical and Applied Genetics, 104, 998-1002.

Meegahakumbura MK (2016) Genetic Assessment of Asian Tea Germplasm and the Domestication History of the Tea Plant (Camellia sinensis). PhD dissertation, University of Chinese Academy of Sciences, Beijing.

Meegahakumbura MK, Wambulwa MC, Thapa KK, Li MM, Möller M, Xu JC, Yang JB, Liu BY, Ranjitkar S, Liu J, Li DZ, Gao LM (2016) Indications for three independent domestication events for the tea plant (Camellia sinensis (L.) O. Kuntze) and new insights into the origin of tea germplasm in China and India revealed by nuclear microsatellites. PLoS ONE, 11, e155369.

Ming TL (1992) A revision of Camellia Sect. Thea. Acta Botanica Yunnanica, 14, 115-132. (in Chinese with English abstract) [闵天禄 (1992) 山茶属茶组植物的订正. 云南 植物研究, 14, 115-132.]

Ming TL (2000) Monograph of the Genus Camellia. Yunnan Science and Technology Press, Kunming. [闵天禄 (2000) 世界山茶属的研究. 云南科学技术出版社, 昆明.]

Mondal TK (2002) Assessment of genetic diversity of tea (Camellia sinensis (L.) O. Kuntze) by inter-simple sequence repeat polymerase chain reaction. Euphytica, 128, 307-315.

Paul S, Wachira FN, Powell W, Waugh R (1997) Diversity and genetic differentiation among populations of Indian and Kenyan tea (Camellia sinensis (L.) O. Kuntze) revealed by 
AFLP markers. Theoretical and Applied Genetics, 94, 255-263.

Peng CL (2015) Study of the serrated Zhang tablets from North Vietnam. Huaxia Archaeology, (1), 63-71. (in Chinese with English abstract) [彭长林 (2015) 越南北部牙璋研究. 华 夏考古, (1), 63-71.]

Perrier X, De Langhe E, Donohue M, Lentfer C, Vrydaghs L, Bakry F, Carreel F, Hippolyte I, Horry JP, Jenny C, Lebot V, Risterucci AM, Tomekpe K, Doutrelepont H, Ball T, Manwaring J, de Maret P, Denham T (2011) Multidisciplinary perspectives on banana (Musa spp.) domestication. Proceedings of the National Academy of Sciences, USA, 108, 11311-11318.

Qiao TT, Ma CL, Zhou YH, Yao MZ, Liu R, Chen L (2010) EST-SSR genetic diversity and population structure of tea landraces and developed cultivars (lines) in Zhejiang Province, China. Acta Agronomica Sinica, 36, 744-753. (in Chinese with English abstract) [乔婷婷, 马春雷, 周炎花, 姚明哲, 刘饶, 陈亮 (2010) 浙江省茶树地方品种与选育 品种遗传多样性和群体结构的EST-SSR分析. 作物学报, 36, 744-753.]

Raina SN, Ahuja PS, Sharma RK, Das SC, Bhardwaj P, Negi R, Sharma V, Singh SS, Sud RK, Kalia RK, Pandey V, Banik J, Razdan V, Sehgal D, Dar TH, Kumar A, Bali S, Bhat V, Sharma S, Prasanna BM, Goel S, Negi MS, Vijayan P, Tripathi SB, Bera B, Hazarika M, Mandal AKA, Kumar RR, Vijayan D, Ramkumar S, Chowdhury BR, Mandi SS (2012) Genetic structure and diversity of India hybrid tea. Genetic Resources and Crop Evolution, 59, 1527-1541.

Sealy JH (1958) A Revision of the Genus Camellia. Edward Arnold Ltd., London.

Sharma RK, Negi MS, Sharma S, Bhardwaj P, Kumar R, Bhattachrya E, Tripathi SB, Vijayan D, Baruah AR, Das SC, Bera B, Rajkumar R, Thomas J, Sud RK, Muraleedharan N, Hazarika M, Lakshmikumaran M, Raina SN, Ahuja PS (2010) AFLP-based genetic diversity assessment of commercially important tea germplasm in India. Biochemical Genetics, 48, 549-564.

Suzuki S, Zheng YF, Noshiro S, Oyama M, Nakamura S, Murakami Y (2011) Identification of tree species of archaeological woods from Tianluoshan Site in Zhejiang Province. In: Integrated Studies on Natural Remains from Tianluoshan (eds Center for the Study of Chinese Archaeology, Peking University, Zhejiang Province Institute of Archaeology and Cultural Heritage), pp. 108-117. Cultural Relics Press, Beijing. (in Chinese) [铃木三郎, 郑云飞, 能城修一, 大山干 成, 中村慎一, 村上由美子 (2011) 浙江省田螺山出土木 材的树种鉴定. 见: 田螺山遗址自然遗存综合研究(北京 大学中国考古学研究中心, 浙江省文物考古研究所编), 108-117页. 文物出版社, 北京.]

Taknet DK (2002) The Heritage of Indian Tea. Jaipur, IIME.

Taniguchi F, Kimura K, Saba T, Ogino A, Yamaguchi S, Tanaka J (2014) Worldwide core collections of tea (Camellia sinensis) based on SSR markers. Tree Genetics \& Genomes, 10, 1555-1565.

Tian YH, Liang YF, Yan DH, Luo XY, Zhou GL (2008) Geography distribution and ecotypes of wild tea resources in Guizhou. Guizhou Agricultural Sciences, (2), 160-161. (in Chinese with English abstract) [田永辉, 梁远发, 跒东海, 罗显扬, 周国兰 (2008) 贵州野生茶树资源的地理分布 与生态型. 贵州农业科学, (2), 160-161.]

Wachira FN, Waugh R, Hackett CA, Powell W (1995) Detection of genetic diversity in tea (Camellia sinensis) using RAPD markers. Genome, 38, 201-210.

Wambulwa MC, Meegahakumbura MK, Kamunya S, Muchugi A, Moller M, Liu J, Xu JC, Ranjitkar S, Li DZ, Gao LM (2016a) Insights into the genetic relationships and breeding patterns of the African tea germplasm based on nSSR markers and cpDNA sequences. Frontiers in Plant Science, 7, 1244-1255.

Wambulwa MC, Meegahakumbura MK, Chalo R, Kamunya S, Muchugi A, Xu JC, Liu J, Li DZ, Gao LM (2016b) Nuclear microsatellites reveal the genetic architecture and breeding history of tea germplasm of East Africa. Tree Genetics \& Genomes, 12, 11-22.

Wambulwa MC, Meegahakumbura MK, Kamunya S, Muchugi A, Möller M, Xu JC, Liu J, Li DZ, Gao LM (2017) Multiple origins and a narrow genepool characterise the African tea germplasm: Concordant patterns revealed by nuclear and plastid DNA markers. Scientific Reports, 7, 4053-4061.

Wang PS, Yu FL (2002) The geographic distribution, diversity and utilization of wild tea camellias in China. Journal of Tea Science, 22(2), 105-108, 134. (in Chinese with English abstract) [王平盛, 虞富莲 (2002) 中国野生大茶树的地理 分布、多样性及其利用价值. 茶叶科学, 22, 105-108, 134.]

Wang ZL (2016) The Blang people’s vocabulary and historical changes of tea culture. Agricultural Archaeology, (5), 171-175. (in Chinese) [王仲黎 (2016) 布朗族茶文化词汇 与茶文化历史变迁. 农业考古, (5), 171-175.]

Wen HR (2006) Researches on changes of plants and animals in historical periods of China. Chongqing Publishing House, Chongqing. (in Chinese) [文焕然 (2006) 中国历史时期植 物与动物变迁研究. 重庆出版社, 重庆.]

Wright W (1959) Nomenclature and classification of the tea plant. Nature, 183, 1726-1728.

Wight W (1962) Tea classification revised. Current Science, 7, 298-299.

Wu JN, Lü YF, Zhang CC (1979) Southwest China is the origin place of tea tree in the world. Journal of Tea, (1), 5-11. (in Chinese) [吴觉农, 吕允福, 张承春 (1979) 我国西南地区 是世界茶树的原产地. 茶叶, (1), 5-11.]

Xia E, Zhang H, Sheng J, Li K, Zhang Q, Kim C, Zhang Y, Liu Y, Zhu T, Li W, Huang H, Tong Y, Nan H, Shi C, Shi C, Jiang J, Mao S, Jiao J, Zhang D, Zhao Y, Zhao YJ, Zhang L, Liu Y, Liu B, Yu Y, Shao S, Ni D, Eichler EE, Gao L (2017) The tea tree genome provides insights into tea flavor 
and independent evolution of caffeine biosynthesis. Molecular Plant, 10, 866-877.

Xue DB (2015) Original voice of tea and spread of tea in China. Journal of Guizhou Tea, (4), 34-36. (in Chinese) [薛 德炳 (2015) 茶的原始语音与茶在国内的传播. 贵州茶 叶, (4), 34-36.]

Yang H, Wei CL, Liu HW, Wu JL, Li ZG, Zhang L, Jian JB, Li YY, Tai YL, Zhang J, Zhang ZZ, Jiang CJ, Xia T, Wan XC (2016) Genetic divergence between Camellia sinensis and its wild relatives revealed via genome wide SNPs from RAD sequencing. PLoS ONE, 11, e0151424.

Yao GK, Cheng QK (1992) Investigating again the etymology of “tea”. China Tea, (5), 30-32. (in Chinese) [姚国坤, 程启 坤 (1992) “茶”字源再考. 中国茶叶, (5), 30-32.]

Yao M, Ma C, Qiao T, Jin J, Chen L (2012) Diversity distribution and population structure of tea germplasms in China revealed by EST-SSR markers. Tree Genetics \& Genomes, 8, 205-220.

Yu FL (1989) Wild arbor tea in China. China Tea, (2), 6-7. (in Chinese) [虞富莲 (1989) 中国的野生大茶树. 中国茶叶, (2), 6-7.]

Yu FL (2010) Discussion on the root which excavated in Tianluoshan Site. In: Proceedings of the 11th China International Tea Culture Forum and the 4th China, Chongqing (Yongchuan) International Tea Culture and Tourism Festival (ed. Yao GK), pp. 328-334. Central Party Literature Publisher, Beijing. (in Chinese) [虞富莲 (2010) 田螺山遗址出 土树根树种的探讨. 见: 中国第十一届国际茶文化研讨 会暨第四届中国重庆永川国际茶文化旅游节论文集(姚国 坤主编), 328-334页. 中央文献出版社, 北京.]

Zhang H (2009) Economic and cultural exchanges between ancient Shu and Southeast and South Asia in pre-Qin period. Forum on Chinese Culture, (1), 129-134. (in Chinese) [张弘 (2009) 先秦时期古蜀与东南亚、南亚的经济文化交流. 中华文化论坛, (1), 129-134.]

Zhao LL, Chen ZP (1981) The De Ang Epic: Dagu and Daleng. National Geographic, (2), 48-53. (in Chinese) [赵腊林, 陈 志鹏 (1981) 达古达楞格莱标. 华夏地理, (2), 48-53.]

Zhao DW, Yang JB, Yang SX, Kato K, Luo JP (2014) Genetic diversity and domestication origin of tea plant Camellia taliensis (Theaceae) as revealed by microsatellite markers. BMC Plant Biology, 14, 14-25.

Zhejiang Province Institute of Archaeology and Cultural Heritage (2011) Overview of the first stage of archaeological studies (2004-2008) on Tianluoshan. In: Integrated Studies on Natural Remains from Tianluoshan (eds Center for the Study of Chinese Archaeology, Peking University, Zhejiang Province Institute of Archaeology and Cultural Heritage), pp 7-26. Cultural Relics Press, Beijing. (in Chinese) [浙江省文 物考古研究所 (2011) 田螺山遗址第一阶段(2004-2008) 考古工作概述. 见: 田螺山遗址自然遗存综合研究(北京 大学中国考古学研究中心, 浙江省文物考古研究所编), 7-26页. 文物出版社, 北京.]

Zhou C, Zhao YM (2013) Epic of the genesis Dagu and Daleng and its tea culture. Academic Exploration, (8), 68-71. (in Chinese with English abstract) [周灿, 赵燕梅 (2013) 《达 古达楞格莱标》的茶文化内涵. 学术探索, (8), 68-71.]

Zhou JM (1985) Discussion on the tea names and language origin. China Tea, (3), 36-38. (in Chinese) [周靖民 (1985) 试论茶名和语言渊源. 中国茶叶, (3), 36-38.]

Zhou YH, Qiao XY, Ma CL, Qiao TT, Jin JQ, Yao MZ, Chen L (2011) Genetic diversity and structure of tea landraces from Guangxi based on EST-SSR analysis. Scientia Silvae Sinicae, 47(3), 59-67. (in Chinese with English abstract) [周 炎花, 乔小燕, 马春雷, 乔婷婷, 金基强, 姚明哲, 陈亮 (2011) 广西茶树地方品种遗传多样性和遗传结构的 EST-SSR分析. 林业科学, 47(3), 59-67.]

Zhu JF (2015) Are the 6000-year-old tea tree roots wild or cultivated? Questioning and thinking about identification of cultivated tree roots of the genus Camellia from the Tianluoshan Site. Agricultural Archaeology, (5), 196-202. (in Chinese) [竺济法 (2015) 六千年茶树根是自然野生还是 人工栽培的? 关于田螺山出土山茶属树根被确认为人工 栽培的几点质疑和思考. 农业考古, (5), 196-202.]

Zhu KZ (1972) A preliminary study on the climatic fluctuations during the last 5,000 years in China. The Chinese Journal of Archaeology, (1), 15-38. (in Chinese) [竺可桢 (1972) 中 国近五千年来气候变迁的初步研究. 考古学报, (1), 15-38.]

Zhu ZZ (1982) Tea origin time and region. Journal of Tea, (3), 42-44. (in Chinese) [朱自振 (1982) 茶的起源时间和地 区. 茶叶, (3), 42-44.]

Zhu ZZ (1992) Ancient tea matter. In: China Tea Classic (ed. Chen ZM), pp. 1-29. Shanghai Culture Press, Shanghai. (in Chinese) [朱自振 (1992) 古代茶事. 见: 中国茶经(陈宗 禁主编), 1-29页. 上海文化出版社, 上海.]

(责任编委: 葛学军 责任编辑: 黄祥忠) 